\title{
Comano's (Trentino) thermal water interferes with tumour necrosis factor- $\alpha$ expression and interleukin-8 production and secretion by cultured human psoriatic keratinocytes: Yet other mechanisms of its anti-psoriatic action
}

\author{
ILARIA DAL PRA $^{1}$, ANNA CHIARINI ${ }^{1}$, RAFFAELLA PACCHIANA ${ }^{1}$, \\ GIUSEPPE ZUMIANI $^{2}$, MAURO ZANONI ${ }^{3}$ and UBALDO ARMATO ${ }^{1}$ \\ ${ }^{1}$ Histology and Embryology Unit, Department of Biomedical and Surgical Sciences, \\ University of Verona Medical School, Verona I-37134; ${ }^{2}$ Dermatology Operative Unit, \\ Saint Chiara Hospital, Trento I-38100; ${ }^{3}$ Research Centre, Terme di Comano, Trentino, Italy
}

Received June 19, 2006; Accepted October 31, 2006

\begin{abstract}
Thermal balneotherapy with Comano's spa water (CW; Trentino, Italy) is beneficial for psoriasis and other skin disorders but its operative mechanisms are largely unknown. Previously, we showed that $\mathrm{CW}$ interferes with the production and secretion of IL-6 and various VEGF-A isoforms and with CK-16 expression by cultured human psoriatic keratinocytes. In this study, confluent cultures of epidermal keratinocytes isolated from the lesional areas of 9 psoriatic patients were exposed for 11-13 days to DMEM, whose chemicals had been dissolved in either deionised water (DW-DMEM, controls) or CW (CW-DMEM, treated cells), in order to assess the expression and secretion of TNF- $\alpha$ and IL- 8 by such cells. The results gained by means of immunocytochemistry, Western immunoblotting (WB), and ELISA assays showed that $\mathrm{CW}$ exposure significantly downregulated the intracellular levels of TNF- $\alpha$, a key inducer of IL-8, IL-6, and other chemokines. However, no assayable TNF- $\alpha$ secretion occurred in keratinocyte-conditioned DWand CW-DMEM samples. Moreover, the intracellular levels and secretion rates of IL-8 were also markedly reduced in the protein extracts and conditioned media of CW-DMEMincubated keratinocytes. Notably, the most effective
\end{abstract}

Correspondence to: Professor Ubaldo Armato, Histology and Embryology Unit, Department of Biomedical and Surgical Sciences, University of Verona Medical School, Strada Le Grazie 8, Verona I-37134, Italy

E-mail: ubaldo.armato@univr.it

Abbreviations: CW, Comano's thermal water; DW, deionised water; IL-8, interleukin-8; sIL-8, secreted IL-8; TNF- $\alpha$, tumour necrosis factor- $\alpha, \mathrm{WB}$, Western immunoblotting

Key words: chemokines, Comano's thermal water, tumour necrosis factor- $\alpha$, cytokines, human keratinocytes, interleukin- 8 , psoriasis inhibition of IL- 8 secretion was elicited by a $25 \% \mathrm{CW}$ fraction in the DMEM. Altogether, our findings indicate that by attenuating at lesional skin sites the deregulated production and secretion of a cascade of several cytokines and chemokines (e.g. TNF- $\alpha$, IL-8, IL-6, and various VEGF-A isoforms), and by offsetting the keratinocytes' abnormal differentiation program entailing CK-16 expression, $\mathrm{CW}$ balneotherapy may beneficially influence the clinical manifestations of psoriasis.

\section{Introduction}

Psoriasis, a chronic inflammatory dermatosis affecting approximately $2 \%$ of the Western population, is clinically marked by relapsing-remitting manifestations of well-defined, symmetrical erythematous plaques covered by scales. Albeit genetically founded, the pathogenesis of psoriasis remains unclear (1). Currently, psoriasis is believed to be a T lymphocyte-driven disorder (2). However, the formation of tortuous, dilated, inflamed, and hyper-permeable venous limbs of capillary plexuses in the upper dermal papillae precedes the plaque's epidermal hyperplasia and dermal infiltration by inflammatory cells (i.e. neutrophils, T lymphocytes, monocytes) (3-6). It has been suggested that psoriasis is an angioproliferative ailment due to the local release of angiogenic molecules by the epidermis (7-10). Local fibroblast activation and increased production and release by keratinocytes of several cytokines and chemokines, such as interleukin-1 (IL-1), tumour necrosis factor- $\alpha$ (TNF- $\alpha$ ), IL-6, IL-8, IL-20, vascular endothelial growth factor-A (VEGF-A) isoforms, endothelial cell stimulating angiogenesis factor (ESAF), transforming growth factor- $\alpha$ (TGF- $\alpha$ ), amphiregulin, and platelet-derived endothelial cell growth factor/thymidine phosphorylase (TP), are also typical features of the disease $(9,11-18)$.

Several lines of evidence indicate that IL- 8 is a C-X-C chemokine partaking in the psoriatic cytokine network $(15,19-24)$ and being thus involved in the pathogenesis of psoriasis $(15,19-26)$. In psoriasis, IL-8 acts as a factor promoting epidermal hyperplasia (27), as a strong chemo- 
Table I. Components of Comano's water. ${ }^{a}$

\begin{tabular}{ll}
\hline Ions & $\mathrm{mM}$ \\
\hline Sodium & 0.182 \\
Potassium & 0.026 \\
Magnesium & 1.010 \\
Calcium & 2.440 \\
Bicarbonate & 6.340 \\
Chloride & 0.047 \\
Sulfuric acid & 0.144 \\
Silicon & 0.163 \\
Fluorine & 0.048 \\
Lithium & 0.0002 \\
Aluminum & 0.00246 \\
Manganese & 0.00064 \\
Iron & 0.0038 \\
Copper & 0.0017 \\
Zinc & 0.00143 \\
Strontium & 0.00605 \\
\hline
\end{tabular}

${ }^{a}$ This water is hypotonic as its dry residue amounts to only $190 \mathrm{mg} / \mathrm{l}$.

attractant for $\mathrm{T}$ lymphocytes, neutrophils, basophils, and mastcells (28-32), and as a stimulant of dermal neoangiogenesis (20). Psoriatic lesional skin contains high amounts of IL-8 mRNA and protein $(19,22,24,25)$. IL-8 synthesis on the part of epidermal, dermal and infiltrating inflammatory cells is stimulated by several cytokines, such as IL-1, TNF- $\alpha$, GM-CSF, and IFN- $\gamma(19,26,33)$. However, keratinocytes and neutrophils are IL-8's main sources $(22,24)$. A heightened expression of IL-8's receptor also occurs in psoriatic lesional epidermis $(23,26)$. Thus, an autocrine loop involving IL-8 and its receptor favours the setting off of the psoriatic epidermal hyperplasia $(26,27)$. Serum levels of IL-8, like those of TNF- $\alpha$, IL-6, IL-12, IL-18 and IFN- $\gamma$, are much higher in patients with active psoriasis than in healthy controls $(34,35)$.

As mentioned above, psoriatic lesional skin overexpresses TNF- $\alpha$, a key cytokine involved in the pathogenetic mechanisms sustaining several inflammatory skin illnesses (12,15,20,33,35-38). Resident dermal cells (fibroblasts, mast-cells) and infiltrated antigen-presenting cells (APCs), macrophages, and $\mathrm{T}$ lymphocytes also express TNF- $\alpha$ (38). The early-occurring TNF- $\alpha$ overproduction and hyper-secretion in psoriasis vulgaris, and in its recalcitrant generalised pustular (von Zumbusch) form (39-41) favours the cellular infiltration of epidermal and dermal layers by eliciting the expression of intercellular adhesion molecules such as ICAM-1, V-CAM-1, and E-selectin by the keratinocytes and endothelial cells (42). In synergism with IFN- $\gamma$ and IL- $1, \mathrm{TNF}-\alpha$ acts as a proinflammatory agent by up-regulating cytokines and chemokines such as IL-8 (19,20,43), IL-6, IL-1, leukemia inhibitory factor (LIF), GM-CSF (43), and TGF- $\alpha$ (19). Moreover, TNF- $\alpha$ stimulates the production of arachidonate cascade derivatives such as leukotriene $\mathrm{B}_{4}\left(\mathrm{LTB}_{4}\right)$ and prostaglandin $\mathrm{E}_{2}\left(\mathrm{PGE}_{2}\right)$, and of oxygen radicals (superoxide anions) (43). TNF- $\alpha$ expression is up-regulated by several cytokines, such as IL-1, IL-2, GM-CSF, and IFN- $\gamma$ (43).

Comano (Trentino, Italy) spa's water $(\mathrm{CW})$ is a thermal hypotonic water containing various electrolytes (Table I). The major dermatological diseases so far treated via $\mathrm{CW}$ balneotherapy are psoriasis and atopic dermatitis (44). Other dermatoses also cared for with $\mathrm{CW}$ include contact dermatitis, seborrhoeic dermatitis, lichen planus, and palmo-plantar keratosis (44). Previous in vivo studies showed the effectiveness of CW balneotherapy in the treatment of psoriasis, since it both significantly lessened hyper-keratosis, acantosis, and dermal papillomatosis and improved skin hydration (44). It must be recalled here that the permeability barrier of normal epidermis is severely disturbed in psoriatic skin (45-47), and that bathing in hypotonic salt solutions triggers antiinflammatory effects in lesional skin sites (48). However, most of the mechanisms through which the clinical signs of psoriasis (and of the other above mentioned skin disorders) are improved by means of CW balneotherapy have not as yet been clarified.

In previous studies $(49,50)$, we showed that exposure to CW interferes with IL-6, VEGF-A isoform, and CK-16 expression by human psoriatic keratinocytes. To further clarify the mechanisms involved in the therapeutic effectiveness of CW balneotherapy in psoriasis, in this study we investigated CW's effects on TNF- $\alpha$ and IL- 8 production and secretion by epidermal keratinocytes isolated from lesional skin biopsies and kept in confluent cultures. Here, we will show that the addition of $\mathrm{CW}$ (in total or partial stead of DW) to the growth medium remarkably hinders the hyper-expression of TNF- $\alpha$ and the heightened production and release of IL- 8 on the part of the psoriatic keratinocytes. Therefore, our previous $(49,50)$ and present findings are consistent with $\mathrm{CW}$ being endowed with a complex phenotype- and cytokine/chemokine-regulating potential that translates into valuable anti-psoriatic therapeutic benefits.

\section{Materials and methods}

In vitro cell culture. Human epidermal keratinocytes were isolated from skin biopsies taken, after informed consent, from 9 psoriatic patients. After rapidly reaching the laboratory, the biopsies were incubated at $4^{\circ} \mathrm{C}$ overnight in a dispase II solution $(0.25 \% \mathrm{w} / \mathrm{v}$; Roche, Milan, Italy). Weak enzymatic digestion allowed the epidermis (as a single lamina) to easily detach from the underlying dermis and subcutaneous tissue. By incubating the isolated epidermal sheet in trypsin solutions $(0.25 \% \mathrm{w} / \mathrm{v})$, suspensions of keratinocytes were obtained. Trypsin's action was next inhibited by adding an excess of serum, and the cell suspensions were soon spun down at $600 \mathrm{rpm}$ for $10 \mathrm{~min}$ at $4^{\circ} \mathrm{C}$. The supernatants were decanted, the pellets resuspended, and the living cells counted in a Neubauer chamber. Keratinocytes were next seeded into plastic flasks pre-coated with a feeder-layer of preirradiated 3T3-J2 cells. To expand the keratinocytes' population, MCDB153:1 medium [consisting of three parts of Dulbecco's modified Eagle's medium (DMEM) and one part of F12 medium; Sigma-Aldrich, Milan, Italy] was used, to which 
foetal bovine serum (FBS; 10\% v/v; BioWhittaker Europe, Belgium), antibiotics (solution of penicillin-streptomycin $1 \% \mathrm{w} / \mathrm{v}$; BioWhittaker), epidermal growth factor (EGF; $0.1 \mu \mathrm{g} \mathrm{ml}^{-1}$; PeproTech, UK), insulin (20 ng ml${ }^{-1}$; PeproTech), and hydrocortisone $\left(0.5 \mu \mathrm{g} \mathrm{ml}^{-1}\right.$; PeproTech) were added. This medium was replaced every two days with fresh samples of the same medium. Human psoriatic keratinocytes proliferated rapidly starting from minute clusters and formed a single layer of small and highly adherent epithelial cells. They had a mitotic doubling time of approximately $48 \mathrm{~h}$. Once cultured in vitro, such keratinocytes kept steadily secreting into the medium, as determined by ELISA assays, amounts of IL-8 at least 6-fold greater than do normal keratinocytes (51).

Experimental protocol. Psoriatic keratinocytes were detached from the culture flasks by a mild trypsin treatment and then seeded at $1.0 \times 10^{6}$ cells into wells containing $2.0 \mathrm{ml}$ of either DMEM medium, whose chemical constituents had been dissolved in DW (controls in DW-DMEM), or in one of three different CW-DMEM media, in which DW had been totally $(100 \%)$ or in part $(50 \%$ or $25 \%)$ substituted with CW. Between days 3 and 11-13 of experimental treatment, the cultured keratinocytes and/or the cell-conditioned media were sampled and their respective contents of TNF- $\alpha$ and IL- 8 determined.

Immunocytochemistry. At chosen time points, psoriatic keratinocytes exposed to either DW- or 100\% CW-DMEM were fixed with absolute methanol at $-20^{\circ} \mathrm{C}$ for $10 \mathrm{~min}$, washed twice with PBS, and permeabilised in $0.1 \%$ Triton X-100 at room temperature for $15 \mathrm{~min}$. Then the cells were washed with PBS-FBS (1\%) (Cambrex BioScience, Milan, Italy) at room temperature for $1 \mathrm{~h}$ and then incubated for $1 \mathrm{~h}$ at $37^{\circ} \mathrm{C}$ with anti-IL-8 mouse monoclonal antibody (final dilution $10 \mu \mathrm{g} \mathrm{ml}^{-1}$; Santa Cruz Biotechnology, Inc., Santa Cruz, CA). Next, keratinocytes were washed three times with PBS-BSA $(1 \%)$ and incubated for $1 \mathrm{~h}$ at room temperature in the dark with specific secondary antibodies (1:100 dilution) conjugated with Alexa Fluor-488 or -555 (Molecular Probes, Invitrogen Corporation, Carlsbad, CA). Control cells not exposed to the primary antibody were always run in parallel. The cells were finally examined under an LSM 510 confocal microscope (Carl Zeiss S.p.A., Milan, Italy).

Western immunoblotting (WB). After 3, 7, and 11 days in vitro, psoriatic keratinocytes kept in $100 \% \mathrm{CW}$ - or in DW-DMEM were scraped into cold PBS and sedimented at $200 \mathrm{x} g$ for $10 \mathrm{~min}$. The sedimented cells were homogenized in T-PER ${ }^{\mathrm{TM}}$ tissue protein extraction reagent (Pierce Chemical Co., Rockford, IL) containing a complete EDTA-free protease inhibitor cocktail (Roche Diagnostics, Monza, Italy). The protein contents of the samples were assayed by Bradford's method (52) using bovine serum albumin as a standard. Equal amounts $(10$ or $20 \mu \mathrm{g})$ of proteins from each cell lysate or cell-conditioned DW- or CW-DMEM $(25 \mu \mathrm{l})$ were boiled in sample buffer $(0.0625 \mathrm{M}$ Tris-HCl, $\mathrm{pH} 6.8,2 \% \mathrm{w} / \mathrm{v}$ SDS, $5 \% \mathrm{w} / \mathrm{v}$ ß-mercaptoethanol, $10 \% \mathrm{v} / \mathrm{v}$ glycerol, $0.002 \% \mathrm{w} / \mathrm{v}$ bromphenol blue) and electrophoresed in $10 \% \mathrm{w} / \mathrm{v}$ SDSpolyacrylamide gel. The separated proteins were blotted onto a nitrocellulose membrane $(0.45 \mu \mathrm{m}$; Bio-Rad Laboratories, Hercules, CA). To immunodetect IL-8 the blots were probed with the same specific primary antibody as used for immunocytochemistry at a final dilution of $1.0 \mu \mathrm{g} \mathrm{ml}^{-1}$. To detect TNF- $\alpha$ the blots were probed with an anti-TNF- $\alpha$ goat polyclonal antibody (Santa Cruz) at a final dilution of $1.0 \mu \mathrm{g} \mathrm{ml}^{-1}$. Blots were next incubated with alkaline phosphatase-conjugated anti-mouse or anti-goat IgG (Santa Cruz), and stained with BCIP/NBT liquid substrate reagent (Sigma). Developed blots were photographed with an Olympus $3300^{\mathrm{TM}}$ digital camera, and the determination of the $\mathrm{M}_{\mathrm{r}}$ and the densitometric analysis of each specific protein band were carried out using Sigmagel $^{\mathrm{TM}}$ software (Jandel Corp., Erkrath, Germany).

ELISA assays of IL-8 and TNF- $\alpha$. Human psoriatic keratinocytes were cultured for up to 13 days in four different growth media containing DMEM components dissolved in the following percent fluid fractions: (i) $\mathrm{CW} 100 \% / \mathrm{DW} 0 \%$; (ii) CW 50\%/DW 50\%; (iii) CW 25\%/DW 75\%; and (iv) CW 0\%/DW $100 \%$ (control medium). Keratinocyte-conditioned samples of the four kinds of growth media were taken at days $3,6,8,10$, and 13 of culture and stored at $-80^{\circ} \mathrm{C}$ to be subsequently assayed for their IL- 8 and TNF- $\alpha$ content. To this aim, specific commercial ELISA kits were used (CLB, Amsterdam, The Netherlands). The tests were performed according to the instructions of the manufacturer. The sensitivity of the assays for both IL- 8 and TNF- $\alpha$ was $4 \mathrm{pg} \mathrm{ml}^{-1}$. The results were expressed as secretion values per duplicate cultures per $10^{6}$ keratinocytes.

Statistical analysis. One-way analysis of variance (ANOVA) with post hoc Bonferroni's test was used to compare mean values and a significance level of $\geq 0.05$ was chosen.

\section{Results}

$C W$ 's effects on intracellular levels of $I L-8$. WB analyses revealed that human psoriatic keratinocytes produced an IL-8 precursor endowed with a molecular mass of $51 \mathrm{kDa}$ (Fig. 1B) (53). Both confocal microscopy (Fig. 1A), WB observations (Fig. 1B), and densitometric determinations (Fig. 1C) showed that by days 3 and 5 after the onset of the experiments in the $100 \%$ CW-DMEM-incubated keratinocytes the intracellular levels of IL-8 had significantly fallen (in WB specimens: at day $3,-86 \%, \mathrm{p}<0.001$; at day $5,-76 \%, \mathrm{p}<0.001)$ with respect to the DW-DMEM-kept (untreated) cells. At day 7, intracellular IL-8 levels became alike in both CW-treated and untreated keratinocytes (Fig. 1A-C), possibly because the untreated cells kept dumping significant amounts of IL-8 into the medium (Fig. 2). Finally, by day 11, in CW-DMEM-kept keratinocytes intracellular IL-8 levels were found to have risen 3.9-fold ( $\mathrm{p}<0.001$ in WB specimens) with respect to 7 -day values, thus becoming 3-fold higher $(\mathrm{p}<0.001)$ than in DW-DMEMincubated cells (Fig. 1A-C). Thus incubating keratinocytes in CW-DMEM medium brought about an early deep cutback followed by a belated intracellular surge of intracellular IL-8 levels. As assessed from the values of the surface areas under the respective curves in Fig. 1C, between days 3 and 11, total IL-8 levels in CW-DMEM-exposed keratinocytes were $56 \%$ lower $(\mathrm{p}<0.001)$ than in their DW-DMEM-kept counterparts. Conceivably, these observations were the result of an early remarkable and persistent down-regulation of IL-8 production, 

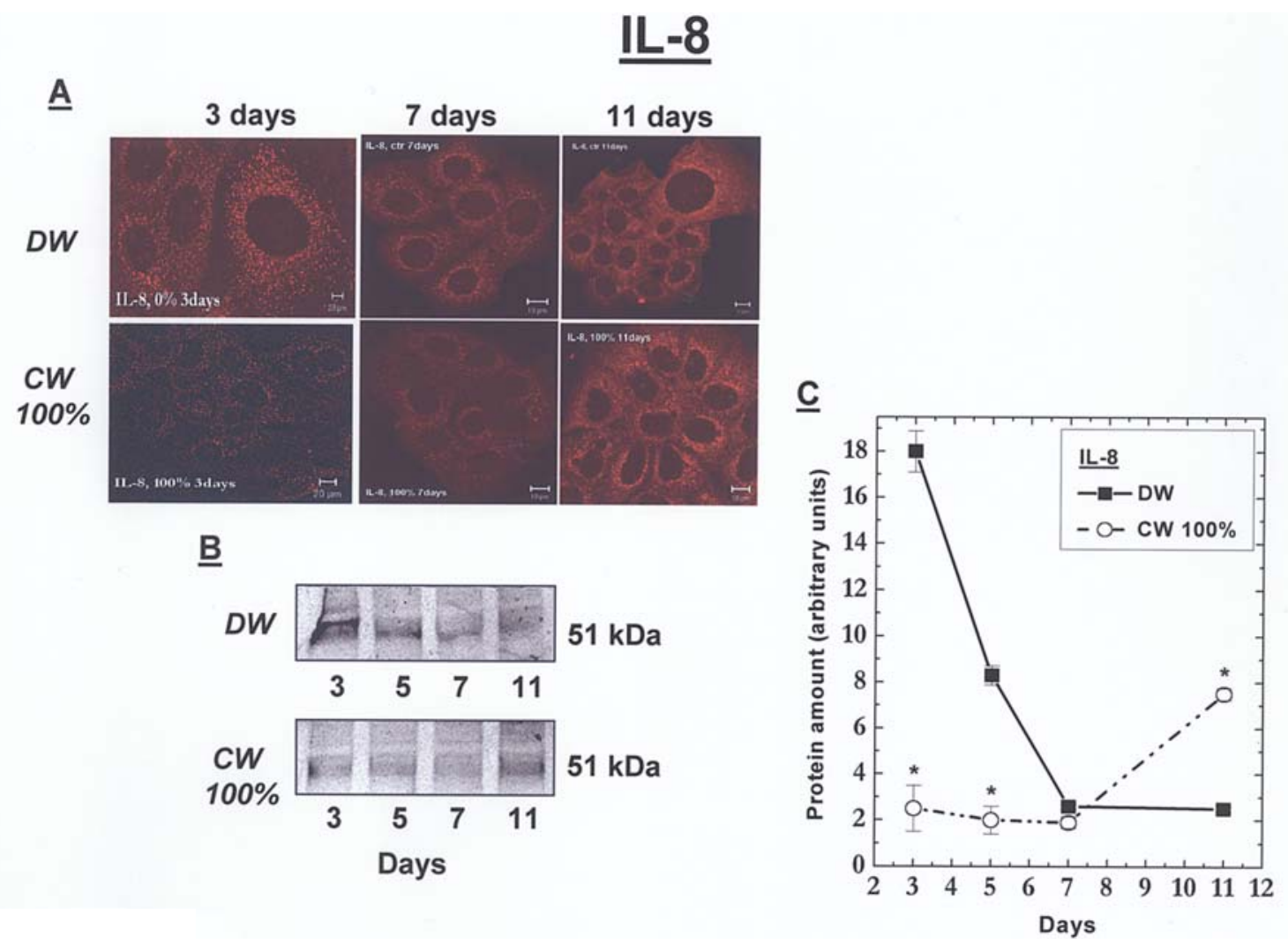

Figure 1. Exposure to CW 100\%-DMEM medium elicited an early, deep down-regulation and a late surge of the intracellular IL-8 levels in cultured otherwise IL-8-overproducing and hyper-secreting psoriatic epidermal keratinocytes. (A) Psoriatic keratinocytes incubated in CW 100\%-DMEM exhibited a decrease up to day 7 and a discrete rise at day 11 of the fluorescent signal specifically related to IL-8 with respect to their untreated (i.e. DW-DMEM-kept) counterparts. The confocal pictures are representative of 9 distinct experiments. WB observations (B) and densitometric analyses (C) showed an early decrease followed by a delayed increase in the intracellular IL-8 levels of CW-treated keratinocytes vs. parallel untreated keratinocytes. The immunoblot shown in B is representative, and the points on the curves in C are means \pm SEM of 9 experiments. ${ }^{*} p<0.001$ between time-corresponding DW-and CW-exposed points.

\section{slL-8}

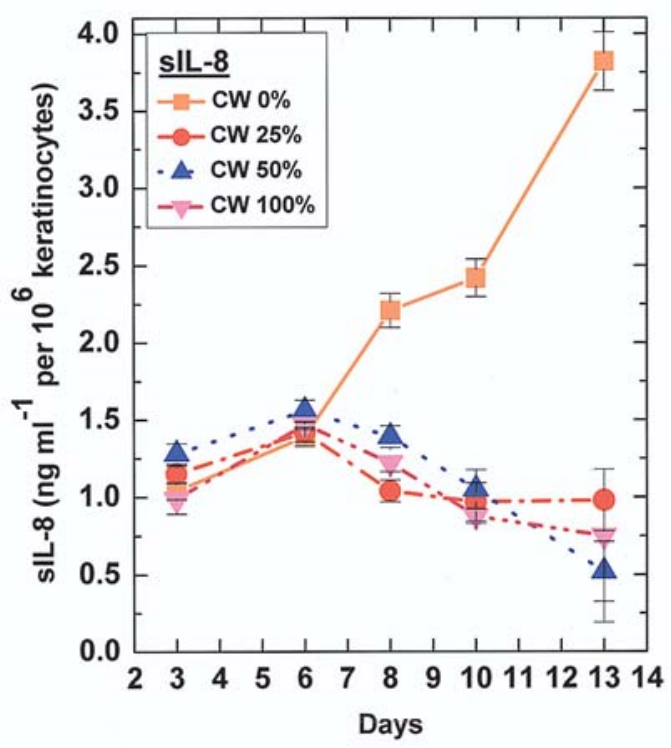

Figure 2. Fractions of CW ranging from $25 \%$ to $100 \%$ in the DMEM medium deeply and progressively curtailed the hyper-secretion of IL-8 on the part of cultured psoriatic keratinocytes bringing it somewhat closer to within normal range values (i.e. 50 - to 150 -ng $\mathrm{ml}^{-1}$ per $10^{6}$ cells) (51). Points on the curves are means from 9 experiments carried out in duplicate. Between day 6 and 13 all values pertaining to CM-treated keratinocytes exhibited a statistical significance of $\mathrm{p}<0.001$ vs. the values of time-corresponding DW-DMEMincubated (control) cells. sIL-8, IL-8 secreted into the growth media. onto which a progressively stronger hindrance of IL-8 secretion was lately superimposed.

$C W$ 's effects on IL-8 secretion. When untreated (i.e. incubated in DW-DMEM), the psoriatic keratinocytes released from the third day onwards increasing amounts of IL-8 $\left(\leq 3.8 \mathrm{ng} \mathrm{ml}^{-1}\right.$ per $10^{6}$ cells) into the medium (Fig. 2). However, once keratinocytes were exposed to DMEM containing various percentages (i.e. from $25 \%$ to $100 \%$ ) of $\mathrm{CW}$ fractions, the IL-8secreting activity was strikingly and progressively decreased from day 6 onwards (e.g., at day 8, from $-38 \%$ to $-54 \%$; and at day 13 , from $-74 \%$ to $-87 \% ; \mathrm{p}<0.001$ vs. parallel untreated controls in both instances) (Fig. 2). Most interestingly, a nearly maximum inhibitory effect on IL-8 secretion was achieved by keeping keratinocytes in CW 25\%/DW 75\%-DMEM (Fig. 2). Hence, as assessed from the values of the surface areas under the respective curves in Fig. 2, an exposure between days 3 and 13 to $\mathrm{CW}$ fractions ranging from $25 \%$ to $100 \%$ in the DMEM similarly reduced from $-47 \%$ to $-51 \%$ $(\mathrm{p}<0.001)$ the total amount of secreted IL-8 (sIL-8) with respect to that dumped by untreated keratinocytes into the DW-DMEM.

$C W$ 's effects on TNF- $\alpha$ expression and secretion. The results of preliminary WB observations and corresponding densitometric assessments showed that after a 5-day exposure to $100 \% \mathrm{CW}$-DMEM, the density of the TNF- $\alpha$-specific $45-\mathrm{kDa}$ 


\section{$\underline{\text { TNF }-\alpha}$}
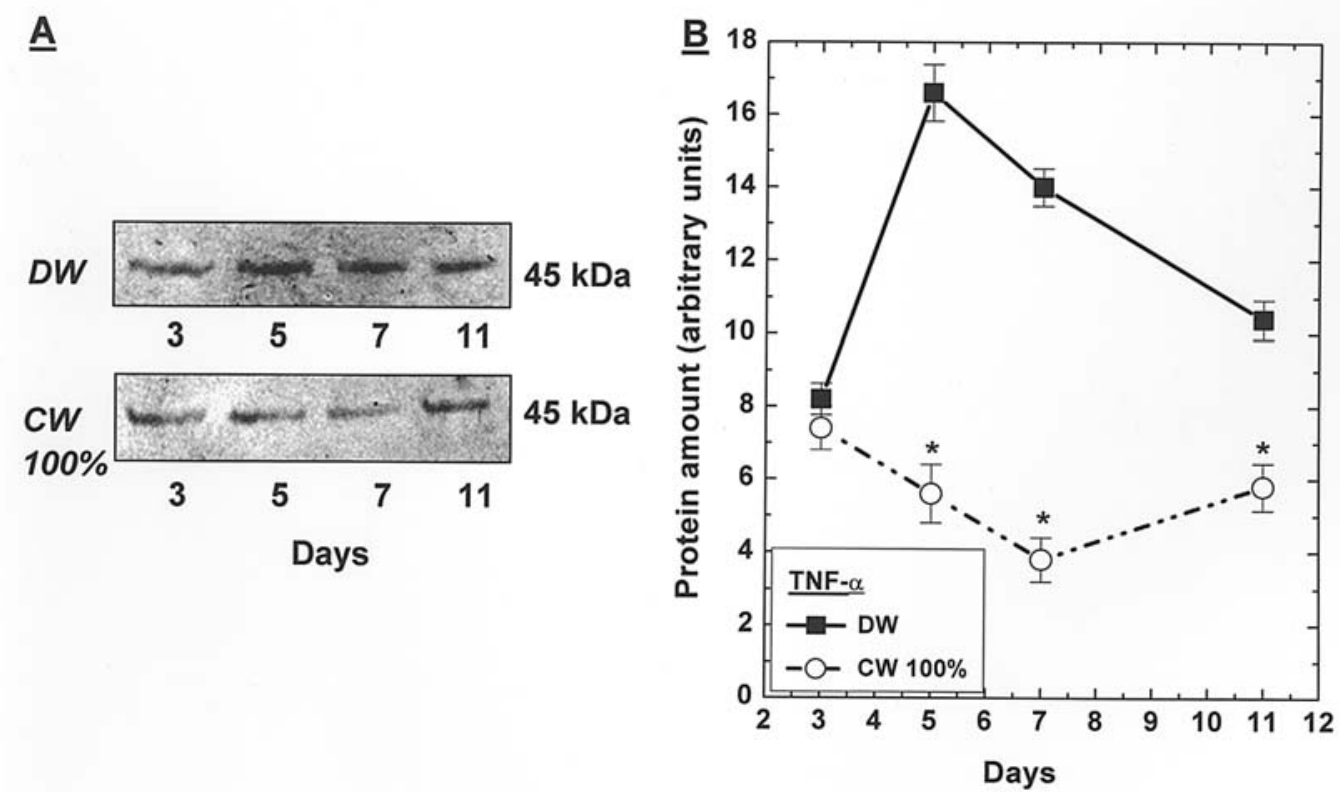

Figure 3. Exposure to CW persistently down-regulated the expression of TNF- $\alpha$ by human lesional keratinocytes cultured in vitro. WB observations (A) and densitometric analyses (B) showed that a strong and persistent down-regulation of TNF- $\alpha$ took place in CW-DMEM-kept keratinocytes with respect to DWDMEM-incubated keratinocytes. By estimating the surface areas under the curves it can be concluded that between days 3 and 11 the incubation in CWDMEM reduced by $-54 \%$ on average $(\mathrm{p}<0.001)$ the expression of TNF- $\alpha$ by cultured psoriatic keratinocytes with respect to that by untreated cells. The immunoblot shown in A is typical, and the points on the curves in B are means \pm SEM of 9 experiments. " $\mathrm{p}<0.001$ between the values pertaining to timecorresponding keratinocyte samples kept in either DW- or CW-DMEM.

protein band had diminished by $-66.3 \%(\mathrm{p}<0.001)$ with respect to that of parallel DW-DMEM-incubated keratinocytes (Fig. 3A and B). Moreover, a 7-day exposure to $100 \% \mathrm{CW}$ DMEM elicited the largest decrease in the density of the TNF- $\alpha$-specific protein band (day 7, $-72.9 \%$; $\mathrm{p}<0.001$ ) vs. that of time-corresponding DW-DMEM-kept keratinocytes (Fig. 3A and B). By day $11 \mathrm{CW}$-treated keratinocytes were found to express TNF- $\alpha$ moieties again at the day 5 levels, which were still $44 \%$ lower than those of their untreated (DW-DMEM-kept) parallel counterparts (Fig. 3A and B). Therefore, as assessed from the values of the surface areas under the respective curves in Fig. 3B, between days 3 and 11 the exposure to $\mathrm{CW}$ curtailed by $-54 \%(\mathrm{p}<0.001)$ the total expression of TNF- $\alpha$ by cultured human epidermal keratinocytes with respect to untreated DW-DMEM-kept counterparts.

On the other hand, by using TNF- $\alpha$-specific ELISA assays we were unable to detect any measurable amount whatsoever of secreted TNF- $\alpha$ in any of the keratinocyte-conditioned samples of DW- or CW-DMEM media tested (data not shown).

\section{Discussion}

In this study, we tested CW's effects on the up-regulated production and secretion of IL-8 on the part of psoriatic keratinocytes kept in pure in vitro cultures, i.e. in the complete absence of $\mathrm{T}$ cells (54). Our findings show that the addition of CW (instead of DW) to the DMEM significantly curtailed both the heightened intracellular levels and secretion rates of IL- 8 by these cells. Notably, IL- 8 hyper-secretion was cut down by incubating the psoriatic keratinocytes in a DMEM whose CW fraction was as little as $25 \%$. This increasingly effective inhibition of IL-8 release by $\mathrm{CW}$ went so far as to elicit a late discrete intracellular IL- 8 accumulation even though its production had concurrently been down-regulated. The operative mechanisms underlying these IL-8-interfering effects elicited by $\mathrm{CW}$ components in psoriatic keratinocytes remain to be elucidated. Nuclear factor $(\mathrm{NF})-\kappa \mathrm{B}$ is a transcription factor that modulates the expression of genes encoding cytokines such as IL-8, IL-6, colony stimulating factors, adhesion molecules, and immune receptors (55). Notably, TNF- $\alpha$ partakes in the activation of NF- $\kappa \mathrm{B}$, thereby acting as a significant modulator of the expression of several pro-inflammatory compounds in psoriasis $(12,15,19)$.

In keeping with this view, the present results show that $\mathrm{CW}$ exposure also significantly interferes with the expression of TNF- $\alpha$ by the cultured psoriatic keratinocytes. Hence, it seems conceivable to ascribe the previously observed interfering effects of CW on IL-6 production and secretion (50) and the presently reported hindering of IL- 8 synthesis and release by $\mathrm{CW}$ to an up-stream inhibition of TNF- $\alpha$ expression by the same CW components.

It is well established that TNF- $\alpha$ plays a major role in psoriasis pathogenesis and progression (40). Clinical improvements of psoriasis associate with a fall in lesional skin and serum TNF- $\alpha$ levels $(36,56,57)$, whereas clinical aggravations of psoriatic area severity index (PASI) scores concur with surges in serum and lesional skin TNF- $\alpha$ concentrations $(40,60)$. Neutralisation of TNF- $\alpha$ by infliximab, an 
anti-TNF- $\alpha$-specific chimerical monoclonal antibody, or by etanercept, a soluble p75 TNF receptor fusion protein that binds both TNF and lymphotoxin (LT), is known to cause a rapid and complete remission of psoriasis even in its recalcitrant von Zumbusch form (39-41) and, when associated with methotrexate, of psoriatic arthritis (58-61).

Reportedly, several cytokines, including IL-1, IL-2, GM$\mathrm{CSF}$, and IFN- $\gamma$ up-regulate TNF- $\alpha$ expression (43). Most interestingly, the results of preliminary work carried out in our lab indicate that $\mathrm{CW}$ exposure also significantly downregulates IL-1 expression in cultured psoriatic keratinocytes, thereby justifying the partial drying up of the tumultuous cytokine cascade sustaining clinical psoriatic manifestations $(15,40)$ (manuscript in preparation).

On the other hand, it is conceivable to ascribe the observed absence of any TNF- $\alpha$ secretion by the cultured psoriatic keratinocytes to a lack of activity on the part of the TNF- $\alpha$ converting enzyme (TACE) in such cells $(62,63)$. TACE, also named ADAM 17, is a member of a disintegrin and metalloproteinase (ADAM) family of proteinases and its mRNA is hyper-expressed in lesional psoriatic skin and in cultured normal keratinocytes (63-65). When active, TACE cleaves pro-TNF- $\alpha$ moieties inserted on the plasmalemmal surface, thereby discharging the mature, soluble TNF- $\alpha$ molecules into the environment. However, little is known about the mechanisms modulating TACE's activity. It may depend upon protein kinase $\mathrm{C}$ activation (66) or manifold signalling pathways $(67,68)$. Further study will establish the reasons why TACE, though being hyper-expressed (64), does not function in pure cultures of psoriatic epidermal keratinocytes.

In conclusion, our previous $(49,50)$ and present observations support the view that $\mathrm{CW}$ balneotherapy may elicit its beneficial effects by interfering with an improper local production and secretion of several chemokines and cytokines, including TNF- $\alpha$, IL-8, IL-6, and various VEGF-A isoforms, and by attenuating some facets, such as CK-16 expression, of the psoriatic phenotype, which altogether locally underlie the epidermal hyperplasia and dermal neoangiogenesis, inflammation, and leukocyte infiltration phenomena proper of psoriatic illness.

\section{References}

1. Bowcok AM and Krueger JG: Getting under the skin: the immunogenetics of psoriasis. Nat Rev Immunol 5: 699-711, 2005.

2. Bos JD and De Rie MA: The pathogenesis of psoriasis. Immunol Today 20: 40-46, 1999.

3. Telner P and Fekete Z: The capillary responses in psoriatic skin. J Invest Dermatol 36: 225-230, 1961.

4. Creamer D, Allen MH, Sousa A, Poston R and Barker JN: Localization of endothelial proliferation and microvascular expansion in active plaque psoriasis. Br J Dermatol 136: 859-865, 1997.

5. Braverman IM and Sibley J: Role of the microcirculation in the treatment and pathogenesis of psoriasis. J Invest Dermatol 78: 12-17, 1982.

6. Schubert C and Christophers E: Mast cells and macrophages in early relapsing psoriasis. Arch Dermatol Res 277: 352-358, 1985.

7. Folkman J: Angiogenesis in psoriasis: therapeutic implications. J Invest Dermatol 59: 40-43, 1972.

8. Goodfield M, Hull SM, Holland D, Roberts G, Wood E, Reid S and Cunliffe W: Investigations of the 'active' edge of plaque psoriasis: vascular proliferation precedes changes in epidermal keratin. Br J Dermatol 131: 808-813, 1994.
9. Creamer D, Sullivan D, Bicknell R and Barker J: Angiogenesis in psoriasis. Angiogenesis 5: 231-236, 2002.

10. Barnhill RL, Parkinson EK and Ryan TJ: Supernatants from cultured human epidermal keratinocytes stimulate angiogenesis. Br J Dermatol 110: 273-281, 1984.

11. Nickoloff BJ, Mitra RS, Varani J, Dixit VM and Polverini PJ: Aberrant production of interleukin- 8 and thrombospondin- 1 by psoriatic keratinocytes mediates angiogenesis. Am J Pathol 144: 820-828, 1994.

12. Ettehadi P, Greaves MW, Wallach D, Aderka D and Camp RD: Elevated tumour necrosis factor-alpha (TNF-alpha) biological activity in psoriatic skin lesions. Clin Exp Immunol 96: 146-151, 1994.

13. Elder JT, Fisher GJ, Lindquist PB, Bennett GL, Pittelkow MR, Coffey RJ Jr, Ellingsworth L, Derynck R and Voorhees JJ: Overexpression of transforming growth factor alpha in psoriatic epidermis. Science 243: 811-814, 1989.

14. Creamer D, Jaggar R, Allen M, Bicknell R and Barker J: Overexpression of the angiogenic factor platelet-derived endothelial cell growth factor/thymidine phosphorylase in psoriatic epidermis. Br J Dermatol 137: 851-855, 1997.

15. Bonifati C and Ameglio F: Cytokines in psoriasis. Int J Dermatol 38: 241-251, 1999.

16. Blumberg H, Conklin D, Xu WF, Grossmann A, Brender T, Carollo S, Eagan M, Foster D, Haldeman BA, Hammond A, Haugen H, Jelinek L, Kelly JD, Madden K, Maurer MF, Parrish-Novak J, Prunkard D, Sexson S, Sprecher C, Waggie K, West J, Whitmore TE, Yao L, Kuechle MK, Dale BA and Chandrasekher YA: Interleukin 20: discovery, receptor identification, and role in epidermal function. Cell 104: 9-19, 2001.

17. Detmar M, Brown LF, Claffey KP, Yeo KT, Kocher O, Jackman RW, Berse B and Dvorak HF: Overexpression of vascular permeability factor/vascular endothelial growth factor and its receptors in psoriasis. J Exp Med 180: 1141-1146, 1994.

18. Bhushan M, McLaughlin B, Weiss JB and Griffiths CE: Levels of endothelial cell stimulating angiogenesis factor and vascular endothelial growth factor are elevated in psoriasis. Br J Dermatol 141: 1054-1060, 1999.

19. Nickoloff BJ, Karabin GD, Barker JN, Griffiths CE, Sarma V, Mitra RS, Elder JT, Kunkel SL and Dixit VM: Cellular localization of interleukin- 8 and its inducer, tumor necrosis factor-alpha in psoriasis. Am J Pathol 138: 129-140, 1991.

20. Barker JN, Sarma V, Mitra RS, Dixit VM and Nickoloff BJ: Marked synergism between tumor necrosis factor-alpha and interferon-gamma in regulation of keratinocyte-derived adhesion molecules and chemotactic factors. J Clin Invest 85: 605-608, 1990.

21. Konstantinova NV, Duong DM, Remenyik E, Hazarika P, Chuang A and Duvic M: Interleukin- 8 is induced in skin equivalents and is highest in those derived from psoriatic fibroblasts. J Invest Dermatol 107: 615-621, 1996.

22. Gillitzer R, Berger R, Mielke V, Muller C, Wolff K and Stingl G: Upper keratinocytes of psoriatic skin lesions express high levels of NAP-1/IL-8 mRNA in situ. J Invest Dermatol 97: 73-79, 1991.

23. Beljaards RC, Van Beek P, Nieboer C, Stoof TJ and Boorsma DM: The expression of interleukin- 8 receptor in untreated and treated psoriasis. Arch Dermatol Res 289: 440-443, 1997.

24. Gillitzer R, Ritter U, Spandau U, Goebeler M and Brocker EB: Differential expression of GRO-alpha and IL-8 mRNA in psoriasis: a model for neutrophil migration and accumulation in vivo. J Invest Dermatol 107: 778-782, 1996.

25. Nickoloff BJ: The cytokine network in psoriasis. Arch Dermatol 127: 871-884, 1991.

26. Kemeny L, Ruzicka T, Dobozy A and Michel G: Role of interleukin-8 receptor in skin. Int Arch Allergy Immunol 104: 317-322, 1994.

27. Tuschil A, Lam C, Haslberger A and Lindley I: Interleukin-8 stimulates calcium transients and promotes epidermal cell proliferation. J Invest Dermatol 99: 294-298, 1992.

28. Lindley I, Aschauer H, Seifert JM, Lam C, Brunowsky W, Kownatzki E, Thelen M, Peveri P, Dewald B, von Tscharner V, Waltz A and Baggiolini M: Synthesis and expression in Escherichia coli of the gene encoding monocyte-derived neutrophil-activating factor: biological equivalence between natural and recombinant neutrophil-activating factor. Proc Natl Acad Sci USA 85: 9199-9203, 1988.

29. Larsen CG, Anderson AO, Appella E, Oppenheim JJ and Matsushima K: The neutrophil-activating protein (NAP-1) is also chemotactic for T lymphocytes. Science 243: 1464-1466, 1989. 
30. Leonard EJ, Yoshimura T, Tanaka S and Raffeld M: Neutrophil recruitment by intradermally injected neutrophil attractant/ activation protein-1. J Invest Dermatol 96: 690-694, 1991.

31. Nilsson G, Mikovits JA, Metcalfe DD and Taub DD: Mast cell migratory response to interleukin-8 is mediated through interaction with chemokine receptor CXCR2/Interleukin-8RB. Blood 93: 2791-2797, 1999.

32. Barker JN, Jones ML, Mitra RS, Crockett-Torabe E, Fantone JC, Kunkel SL, Warren JS, Dixit VM and Nickoloff BJ: Modulation of keratinocyte-derived interleukin-8 which is chemotactic for neutrophils and T lymphocytes. Am J Pathol 139: 869-876, 1991.

33. Delaporte E, Bieber T, Viac J, Faure M and Nicolas JF: Cytokines épidermiques et inflammation cutanée. Ann Dermatol Venereol 121: 836-843, 1994.

34. Jacob SE, Nassiri M, Kerdel FA and Vincek V: Simultaneous measurement of multiple Th1 and Th2 serum cytokines in psoriasis and correlation with disease severity. Mediators Inflamm 12: 309-313, 2003.

35. Arican O, Aral M, Sasmaz S and Ciragil P: Serum levels of TNF-alpha, IFN-gamma, IL-6, IL-8, IL-12, IL-17, and IL-18 in patients with active psoriasis and correlation with disease severity. Mediators Inflamm 14: 273-279, 2005.

36. Bonifati C, Carducci M, Cordiali Fei P, Trento E, Sacerdoti G, Fazio $\mathrm{M}$ and Ameglio F: Correlated increases of tumour necrosis factor-alpha, interleukin-6 and granulocyte monocyte-colony stimulating factor levels in suction blister fluids and sera of psoriatic patients - relationships with disease severity. Clin Exp Dermatol 19: 383-387, 1994.

37. Olaniran AK, Baker BS, Paige DG, Garioch JJ, Powles AV and Fry L: Cytokine expression in psoriatic skin lesions during PUVA therapy. Arch Dermatol Res 288: 421-425, 1996.

38. Wakefield PE, James WD, Samlaska CP and Meltzer MS: Tumor necrosis factor. J Am Acad Dermatol 24: 675-685, 1991.

39. Benoit S, Toksoy A, Brocker EB, Gillitzer R and Goebeler M: Treatment of recalcitrant pustular psoriasis with infliximab: effective reduction of chemokine expression. Br J Dermatol 150: 1009-1012, 2004.

40. Gottlieb AB, Chamian F, Masud S, Cardinale I, Abello MV, Lowes MA, Chen F, Magliocco M and Krueger JG: TNF inhibition rapidly down-regulates multiple proinflammatory pathways in psoriasis plaques. J Immunol 175: 2721-2729, 2005.

41. Saini R, Tutrone WD and Weinberg JM: Advances in therapy for psoriasis: an overview of infliximab, etanercept, efalizumab, alefacept, adalimumab, tazarotene, and pimecrolimus. Curr Pharm Des 11: 273-280, 2005.

42. Groves RW, Allen MH, Ross EL, Barker JN and MacDonald DM: Tumor necrosis factor alpha is pro-inflammatory in normal human skin and modulates cutaneous adhesion molecule expression. $\mathrm{Br}$ J Dermatol 132: 345-352, 1995.

43. Aggarwal BB and Natarajan K: Tumor necrosis factors: developments during the last decade. Eur Cytokine Netw 7: 93-124, 1996

44. Zumiani G, Zanoni M and Agostini G: Valutazione dell'efficacia dell'acqua della fonte termale di Comano versus acqua di acquedotto nella cura della psoriasi. G Ital Dermatol Venereol 135: $1-5,2000$.

45. Grice KA: Transepidermal water loss in pathological skin. In: Physiology and Pathophysiology of the Skin. Jarret A (ed). Academic Press, London, pp2147-2155, 1980.

46. Harding CR: The stratum corneum: structure and function in health and disease. Dermatol Ther 17 (suppl 1): 6-15, 2004.

47. Madison KC: Barrier function of the skin: 'la raison d'etre' of the epidermis. J Invest Dermatol 121: 231-241, 2003.

48. Tsoureli-Nikita E, Menchini G, Ghersetich I and Hercogova J: Alternative treatment of psoriasis with balneotherapy using Leopoldine spa water. J Eur Acad Dermatol Venereol 16: 260-262, 2002.

49. Chiarini A, Dal Pra I, Pacchiana R, Menapace L, Zumiani G, Zanoni $\mathrm{M}$ and Armato U: Comano's (Trentino) thermal water interferes with the expression and secretion of vascular endothelial growth factor-A (VEGF-A) protein isoforms by cultured human psoriatic keratinocytes: A potential mechanism of its anti-psoriatic action. Int J Mol Med 18: 17-25, 2006.
50. Chiarini A, Dal Pra I, Pacchiana R, Zumiani G, Zanoni M and Armato U: Comano's (Trentino) thermal water interferes with interleukin-6 production and secretion and with cytokeratin-16 expression by cultured human psoriatic keratinocytes: Further potential mechanisms of its anti-psoriatic action: Int J Mol Med 18: 1073-1079, 2006.

51. Newby CS, Barr RM, Greaves MW and Mallet AI: Cytokine release and cytotoxicity in human keratinocytes and fibroblasts induced by phenols and sodium dodecyl sulfate. J Invest Dermatol 115: 292-298, 2000

52. Bradford MM: A rapid and sensitive method for the quantitation of microgram quantities of protein utilizing the principle of protein-dye binding. Anal Biochem 72: 248-254, 1976.

53. Sticherling M, Bornscheuer E, Schroder JM and Christophers E: Localization of neutrophil-activating peptide-1/interleukin-8immunoreactivity in normal and psoriatic skin. Invest Dermatol 96: 26-30, 1991

54. Barker CL, McHale MT, Gillies AK, Waller J, Pearce DM, Osborne J, Hutchinson PE, Smith GM and Pringle JH: The development and characterization of an in vitro model of psoriasis. J Invest Dermatol 123: 892-901, 2004.

55. Barnes PJ: Nuclear factor-kappa B. Int J Biochem Cell Biol 29: 867-870, 1997.

56. Mussi A, Bonifati C, Carducci M, D'Agosto G, Pimpinelli F, D'Urso D, D'Auria L, Fazio M and Ameglio F: Serum TNF-alpha levels correlate with disease severity and are reduced by effective therapy in plaque-type psoriasis. J Biol Regul Homeost Agents 11: 115-118, 1997.

57. Ameglio F, Bonifati C, Pietravalle $M$ and Fazio M: Interleukin-6 and tumour necrosis factor levels decrease in the suction blister fluids of psoriatic patients during effective therapy. Dermatology 189: 359-363, 1994

58. Knight DM, Trinh H, Le J, Siegel S, Shealy D, McDonough M, Scallon B, Moore MA, Vilcek J, Daddona P, et al: Construction and initial characterization of a mouse-human chimeric antiTNF antibody. Mol Immunol 30: 1443-1453, 1993.

59. Chaudhari U, Romano P, Mulcahy LD, Dooley LT, Baker DG and Gottlieb AB: Efficacy and safety of infliximab monotherapy for plaque-type psoriasis: a randomised trial. Lancet 357: 1842-1847, 2001.

60. Abuzakouk M, Feighery C and Jackson J: Tumour necrosis factor blocking agents: a new therapeutic modality for inflammatory disorders. Br J Biomed Sci 59: 173-179, 2002.

61. Mease PJ, Goffe BS, Metz J, VanderStoep A, Finck B and Burge DJ: Etanercept in the treatment of psoriatic arthritis and psoriasis: a randomized trial. Lancet 356: 385-390, 2000

62. Moss ML, Jin SL, Becherer JD, Bickett DM, Burkhart W, Chen WJ, Hassler D, Leesnitzer MT, McGeehan G, Milla M, Moyer M, Rocque W, Seaton T, Schoenen F, Warner J and Willard D: Structural features and biochemical properties of TNF-alpha converting enzyme (TACE). J Neuroimmunol 72: 127-129, 1997.

63. Black RA, Rauch CT, Kozlosky CJ, Peschon JJ, Slack JL, Wolfson MF, Castner BJ, Stocking KL, Reddy P, Srinivasan S, Nelson N, Boiani N, Schooley KA, Gerhart M, Davis R, Fitzner JN, Johnson RS, Paxton RJ, March CJ and Cerretti DP: A metalloproteinase disintegrin that releases tumour-necrosis factor-alpha from cells. Nature 385: 729-733, 1997.

64. Kawaguchi M, Mitsuhashi Y and Kondo S: Overexpression of tumour necrosis factor-alpha-converting enzyme in psoriasis. $\mathrm{Br}$ J Dermatol 152: 915-919, 2005.

65. Kawaguchi M, Mitsuhashi Y and Kondo S: Localization of tumour necrosis factor-alpha converting enzyme in normal human skin. Clin Exp Dermatol 29: 185-187, 2004.

66. Hooper NM, Karran EH and Turner AJ: Membrane protein secretases. Biochem J 321: 265-279, 1997.

67. Dethlefsen SM, Raab G, Moses MA, Adam RM, Klagsbrun M and Freeman MR: Extracellular calcium influx stimulates metalloproteinase cleavage and secretion of heparin-binding EGF-like growth factor independently of protein kinase C. J Cell Biochem 69: 143-153, 1998.

68. Vecchi M, Rudolph-Owen LA, Brown CL, Dempsey PJ and Carpenter G: Tyrosine phosphorylation and proteolysis. Pervanadate-induced, metalloprotease-dependent cleavage of the ErbB-4 receptor and amphiregulin. J Biol Chem 273: 20589-20595, 1998. 